\title{
Simulation of Line Outage Distribution Factors (L.O.D.F) Calculation for $\mathrm{N}$-Buses System
}

\author{
Rashid H. AL-Rubayi \\ Department of Electrical \\ Engineering, University of \\ Technology
}

\author{
Afaneen A. Abood \\ Department of Electrical \\ Engineering, University of \\ Technology
}

\author{
Mohammed R. Saeed \\ Alhendawi \\ Department of Electrical \\ Engineering, University of \\ Technology
}

\begin{abstract}
System security involves practices designed to keep the system operating when components fail. A transmission line may be damage by a storm lead to taken out by automatic relaying. If, in committing and dispatching generation, proper regard for transmission flows are maintain, the remaining transmission lines can take the increased loading with still remain within limit. Because the specific times at which initiating events that cause components to fail are unpredictable, the system must be operated at all times in such a way that the system will not be left in a dangerous condition should any credible initiating event occur. Power system equipment are designed to be operate within certain limits most pieces of equipment are protected by automatic devices that can cause equipment to be switched out of the system if these limits are violated. If any event occurs on a system that leaves it operating with limits violated, the event may be follow by a series of further actions that switch other equipment out of service. If this process of cascading failures continues, the entire system or large parts of it may completely collapse. In this paper, it has been building simulation program to study the cases outage lines of the network system. Three cases adopted for the purposes of the study. Where study and discuss those cases in detail and its impact on network performance. It was diagnosed lines, which causes increased power flow over the limit in addition to the reflection of the other feeding lines.
\end{abstract}

\section{Keywords}

Contingency analysis; dc power flow; power system security

\section{INTRODUCTION}

The dc power flow simplifies the power flow by making a number of approximations including 1) completely ignoring the reactive power balance equations, 2) assuming all voltage magnitudes are identically one per unit, 3 ) ignoring line losses and 4) ignoring tap dependence in the transformer reactance. Hence, the dc power flow reduces the power flow problem to a set of linear equations. The dc solution load value has increased to match the total ac load plus losses, a manner to make comparison between the ac and dc solution results possible. The effectiveness of the method developed is identified through its application to a 6 buses test system [1].

\section{DC POWER FLOW}

AC power flow algorithms have high calculation precision but do not have fast speed. In real power dispatch or power market analysis, the requirement of calculation precision is not very high, but the requirement of calculation speed is of most concern, especially for a large - scale power system. More simplification power flow algorithms than fast decoupled power flow algorithms are used. One algorithm is called "MW Only". In this method, the Q - V equation in the fast decoupled power flow model is completely dropped. Only the following $\mathrm{P}-\theta$ equation is used to correct the angle according to the real power mismatch [2].

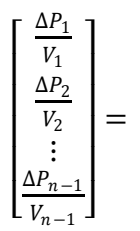

$\left[\begin{array}{ccc}-B_{11} & -B_{12} & -B_{13} \\ -B_{21} & -B_{22} & -B_{23} \\ \vdots & \vdots & \vdots \\ -B_{n-1,1} & -B_{n-1,2} & -B_{n-1, n-1}\end{array}\right]\left[\begin{array}{c}\Delta \theta_{1} \\ \Delta \theta_{2} \\ \vdots \\ \Delta \theta_{n-1}\end{array}\right]$

In the MW - only power flow calculation, the voltage magnitude can be handled either as constant or as 1.0 during each $\mathrm{P}-\theta$ iteration. For the convergence, only real power mismatch is checked no matter what the reactive power mismatch is. Another most simplified power flow algorithm is DC power flow. It is also an MW - only method but has the following assumptions:

1. All the voltage magnitudes are equal to 1.0.

2. Ignore the resistance of the branch; i.e., the susceptance of the branch is

$$
B_{i j}=-\frac{1}{x_{i j}} \ldots \ldots(2)
$$

3. The angle difference on the two ends of the branch is very small, so that we

$$
\begin{aligned}
\sin \theta_{i j}=\theta_{i}- & \theta_{j} \\
& \boldsymbol{c o s} \boldsymbol{\theta}_{\boldsymbol{i} \boldsymbol{j}}=\mathbf{1}
\end{aligned}
$$

(4) Ignore all ground branches; that is,

$$
\begin{gathered}
B_{i 0}=B_{j 0}=0 \\
\cos \theta_{i j}=1
\end{gathered}
$$

Therefore, the DC power flow model will be

Or

$$
\left[\begin{array}{c}
\Delta P_{1} \\
\Delta P_{2} \\
\vdots \\
\Delta P_{n-1}
\end{array}\right]=\left[B^{\prime}\right]\left[\begin{array}{c}
\Delta \theta_{1} \\
\Delta \theta_{2} \\
\vdots \\
\Delta \theta_{n-1}
\end{array}\right]
$$




$$
[\Delta \boldsymbol{P}]=\left[\boldsymbol{B}^{\prime}\right][\Delta \boldsymbol{\theta}]
$$

Where: $\mathrm{B}$ ' matrix are the same as those in the $\mathrm{XB}$ version of fast decoupled power flow but we ignore the matrix B ". That is,

$$
\begin{aligned}
& \boldsymbol{B}_{\boldsymbol{i j}}^{\prime}=-\frac{\mathbf{1}}{\boldsymbol{x}_{\boldsymbol{i j}}} \\
& B_{i j}^{\prime}=-\sum_{j \neq i} B_{i j}^{\prime}
\end{aligned}
$$

The DC power flow is a purely linear equation, so only one iteration calculation is needed to obtain the power flow solution. However, it is only good for calculating real power flows on transmission lines and transformers. The power flowing on each line using the DC power flow is then

$$
P_{i j}=-B_{i j}\left(\theta_{i}-\theta_{j}\right)=\frac{\theta_{i}-\theta_{j}}{x_{i j}} \ldots \ldots(7)
$$

\section{SENSITIVITY CALCULATION}

The sensitivity analyses are becoming more and more important in practical power system operations including in power market operations. These are analyzes and discusses all kinds of sensitivity factors such as loss sensitivity factor, generator shift factor (GSF), constraint shift factor, line outage distribution factor (LODF) and response factor for the transfer path. It also addresses the practical application of these sensitivity factors including a practical method to convert the sensitivities with different references. The power operator uses these to study and monitor market and system behavior and detect possible problems in the operation. These sensitivity calculations are also used to determine whether the online capacity as indicated in the resource plan is located in the right place in the network to serve the forecasted demand. If congestion or violation exists, the generation scheduling based on the sensitivity calculations can determine whether or not a different allocation of the available resources could resolve the congestion or violation problem [3].

The problem of studying thousands of possible outages becomes very difficult to solve if it is desired to present the results quickly. One of the easiest ways to provide a quick calculation of possible overloads is to use linear sensitivity factors. These factors show the approximate change in line flows for changes in generation on the network configuration and are derived from the DC load flow presented in the flowing steps. These factors can be derived in a variety of ways and basically come down to two types [3]:

\section{Generation shift factors.}

\section{Line outage distribution factors.}

Setp1:- Now calculate the $Y_{b u s}$ from impedance $x_{i j}$ as equation

$$
\begin{gathered}
y_{i j}=-\frac{1}{x_{i j}} \ldots \ldots(8) \\
y_{i i}=\sum_{\substack{j=1 \\
i \neq j}}^{n} y_{i j} \ldots \ldots(
\end{gathered}
$$

We gets

$$
Y_{\text {bus }}=\left[\begin{array}{cccc}
y_{11} & y_{12} & \ldots & y_{1 n} \\
y_{21} & \ddots & \ldots & y_{2 n} \\
\vdots & \vdots & \ddots & \vdots \\
y_{n 1} & y_{n 2} & \ldots & y_{n n}
\end{array}\right] \ldots \ldots
$$

Step2:- Since bus one is a slack bus and eliminate (1st row \& the 1st column) from matrix in equation (10). We get

$$
Y_{\text {eliminate }}=\left[\begin{array}{cccc}
y_{22} & y_{23} & \ldots & y_{2 n} \\
y_{32} & \ddots & \ldots & y_{3 n} \\
\vdots & \vdots & \ddots & \vdots \\
y_{n 2} & y_{n 3} & \ldots & y_{n n}
\end{array}\right]
$$

Step3:- Find the inverse of $Y_{\text {eliminate }}$, we gets

$$
M=Y_{\text {eliminate }}^{-1}
$$

Step4:- Determine the sensitivity matrix by :

$$
X=\left[\begin{array}{cc}
0 & 0 \\
0 & M
\end{array}\right]
$$

Step5:- Determine the generation shift sensitivity factor by performing the outage of the generation connected to selected bus (k) with connected line (ll) from the following equation:

$$
a_{l l, k}=\frac{1}{x_{l}}\left(X_{n k}-X_{m k}\right)
$$

Step6:- Determine of the line outage distribution sensitivity factor by performing the outage of the line connected to bus is called (kk) that affected on the line in bus anther line is called (ll) from the following equation:

$$
d_{l l, k k}=\frac{\frac{x_{k k}}{x_{l l}}\left(X_{i n}-X_{j n}-X_{i m}+X_{j m}\right)}{x_{k k}-\left(X_{i i}+X_{j j}-2 X_{i j}\right)} \ldots \ldots
$$

The generation shift factors are designated $\left(\mathrm{a}_{11, \mathrm{i}}\right)$ and have the following definition:

$$
a_{l l, i}=\frac{\Delta f_{l l}}{\Delta P_{i}}
$$

Where:

$$
\begin{aligned}
& l l=\text { line index. } \\
& \mathrm{i}=\text { bus index. }
\end{aligned}
$$

$\Delta f_{l l}=$ change in megawatt power flow on line $l l$ when a change in generation, $\Delta P_{i}$ occurs at bus i.

$$
\Delta P_{i}=\text { change in generation at bus } i \text {. }
$$

It is assumed in this definition that the change in generation, $\Delta \mathrm{P}_{\mathrm{i}}$, is exactly compensated by an opposite change in generation at the reference bus, and that all other generators remain fixed. The $\mathrm{a}_{1, \mathrm{i}} \mathrm{f}$ factor then represents the sensitivity of the flow on line ll to a change in generation at bus i. Suppose one wanted to study the outage of a large generating unit and it was assumed that all the generation lost would be made up by the reference generation (we will deal with the case where the generation is picked up by many machines shortly). If the generator in question was generating $\mathrm{P}_{\mathrm{i}}^{\mathrm{o}} \mathrm{MW}$ and it was lost, we would represent $\Delta \mathrm{P}_{\mathrm{i}}$, as [4]:

$$
\Delta P_{i}=-P_{i}^{o}
$$

And the new power flow on each line in the network could be calculated using a pre calculated set of "a" factors as follows: 


$$
f_{l l}=f_{l l}^{o}+a_{l l, i} \Delta P_{i} \text { for } l l=1 \ldots L L
$$

Where:

$f_{l l}=$ flow on line $l l$ after the generator on bus $\mathrm{i}$ fails.

$$
f_{l l}^{o}=\text { flow before the failure. }
$$

The "outage flow," $f_{l l}$ on each line can be compared to its limit and those exceeding their limit flagged for alarming. This would tell the operations personnel that the loss of the generator on bus i would result in an overload on line 11 .

The line outage distribution factors are used in a similar manner; only hey apply to the testing for overloads when transmission circuits are lost. By definition, the line outage distribution factor has the following meaning:

$$
d_{l l, k}=\frac{\Delta f_{l l}}{f_{k}^{o}} \ldots \ldots
$$

$d_{l l, k}=$ line outage distribution factor when monitoring line 1 after an outage on line $\mathrm{k}$.

$\Delta f_{l l}=$ change in MW flow on line $l$. (opened).

$f_{k}^{o}=$ original flow on line $\mathrm{k}$ before it was outaged

If one knows the power on line $l l$ and line $\mathrm{k}$, the flow on line $l l$ with line $\mathrm{k}$ out can be determined using "d" factors.

$$
f_{l l}=f_{l l}^{o}+d_{l l, k} f_{k}^{o}
$$

Where:

$f_{l l}^{o}, f_{k}^{o}=$ preoutage flows on lines $l l$ and $\mathrm{k}$, respectively.

$$
f_{l l}=\text { flow on line } l l \text { with line } \mathrm{k} \text { out. }
$$

\section{RESULT AND DISCUSSION}

The line and bus data of the IEEE- 6 Bus test system. The system input data is shows in tables $(1,2, \& 3)$.

Table 1: Line Data ${ }^{[5]}$.

\begin{tabular}{|c|c|c|c|}
\hline $\begin{array}{c}\text { From } \\
\text { Bus }\end{array}$ & $\begin{array}{c}\text { To } \\
\text { Bus }\end{array}$ & $\mathbf{R}$ (pu) & $\mathbf{X}(\mathbf{p u})$ \\
\hline 1 & 2 & 0.10 & 0.20 \\
\hline 1 & 4 & 0.05 & 0.20 \\
\hline 1 & 5 & 0.08 & 0.30 \\
\hline 2 & 3 & 0.05 & 0.25 \\
\hline 2 & 4 & 0.05 & 0.10 \\
\hline 2 & 5 & 0.10 & 0.30 \\
\hline 2 & 6 & 0.07 & 0.20 \\
\hline 3 & 5 & 0.12 & 0.26 \\
\hline 3 & 6 & 0.02 & 0.10 \\
\hline 4 & 5 & 0.20 & 0.40 \\
\hline 5 & 6 & 0.10 & 0.30 \\
\hline
\end{tabular}

Table 2: Bus Data ${ }^{[5]}$.

\begin{tabular}{|c|c|c|c|c|}
\hline $\begin{array}{c}\text { Bus } \\
\text { Number }\end{array}$ & $\begin{array}{c}\text { Bus } \\
\text { Type }\end{array}$ & $\begin{array}{c}\text { Voltage } \\
\text { Schedule } \\
(\mathrm{pu} \mathrm{V})\end{array}$ & $\begin{array}{c}\mathrm{P}_{\text {gen. }} \\
(\mathrm{pu} \mathrm{MW})\end{array}$ & $\begin{array}{c}\mathrm{P}_{\text {load }} \\
(\mathrm{pu} \mathrm{MW)}\end{array}$ \\
\hline 1 & Swing & 1.05 & 1.078 & 0.0 \\
\hline 2 & Gen. & 1.05 & 0.50 & 0.0 \\
\hline
\end{tabular}

\begin{tabular}{|c|c|c|c|c|}
\hline 3 & Gen. & 1.07 & 0.60 & 0.0 \\
\hline 4 & Load & & 0.0 & 0.70 \\
\hline 5 & Load & & 0.0 & 0.70 \\
\hline 6 & Load & & 0.0 & 0.70 \\
\hline
\end{tabular}

Table 3: The MW Limits on The Transmission Line.

\begin{tabular}{|c|c|}
\hline Line & $\begin{array}{c}\text { MW } \\
\text { Limit }\end{array}$ \\
\hline $1-2$ & 70 \\
\hline $1-4$ & 90 \\
\hline $1-5$ & 70 \\
\hline $2-3$ & 20 \\
\hline $2-4$ & 50 \\
\hline $2-5$ & 40 \\
\hline $2-6$ & 60 \\
\hline $3-5$ & 30 \\
\hline $3-6$ & 70 \\
\hline $4-5$ & 30 \\
\hline $5-6$ & 20 \\
\hline
\end{tabular}

The simulation program figures $(1 \& 2)$ was used to study multi cases of line outage network as follows:

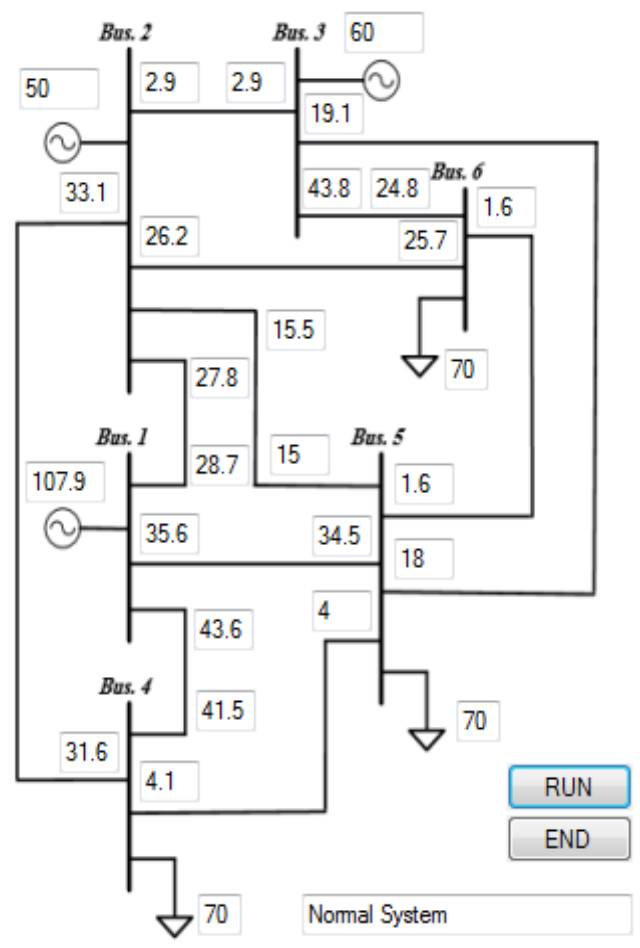

Figure 1: Test System Six-bus network. 


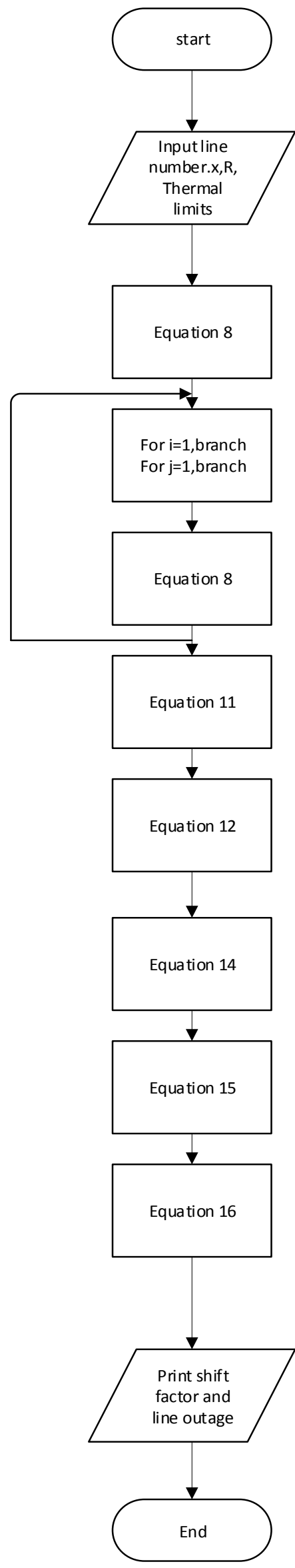

Case 1: (1-2) outage line.

Figures $(3 \& 4)$, it shows that the effect of power flow of the line due to effects of line outage (1-2). This affects leads to redistributing the power flow on the lines of the network system, see table (4).Therefore we see increment and discernment in power flow lines to make that operation of network system. Line (1-4) increase (39.15\%), line (1-5) increase $(32.67 \%)$. Those lines are directly affected by the works to compensate for the network to take advantage of the generator at Bus1. Other lines affected indirectly where the line (2-3) reflected a decrease in the direction of the force of the ability to read $(52 \mathrm{~kW})$. Decreasing power flow lines (2-4, $2-5,2-6$, and $3-5)$ by $(51 \%, 34.71 \%, 13.3 . \%$, and $17.64 \%)$, respectively, at the same time increasing power flow lines (3$6,4-5$, and 5-6) by $(0.01 \%, 4.63 \%$, and $191 \%)$, respectively.

Case 2: (1-4) outage line.

In the event of a defect in the line (1-4), that causes a change in the power flow to the lines of the network, as shown in the table (4). Figures $(5 \& 6)$ shows an increase in the power flow lines $(1-2,1-5,3-6$, and $5-6)$ by $(96.5 \%, 44.7 \%, 0.46 \%$, and $91.25 \%)$ respectively, while the decrease happen applicability capacity of lines $(2-3,2-5,2-6$, and $3-5)$ by $(48.6 \%, 16.58 \%$, $6.33 \%$, and $8.43 \%$ ), respectively. The privacy of the line (4-5) was reflected feed direction to become $(6.16 \mathrm{MW})$. There is a problem in the line (2-4), where the amount of the increase of the power flow is higher than the thermal limits by $(132.88 \%)$.

Case 3: (3-6) outage line.

The outage line (3-6) for technical reasons lead to an increase in the power flow is higher than the thermal limit in two lines, the first (3-5) be increase (133\%) The second line (2-3) which become counterproductive by feeding (20.11 MW), see table (4). In the other hand are increase in lines (1-2, 1-4, 2-6, and $5-6)$ by $(2 \%, 0.4 \% .97 .67 \%$, and $113 \%)$, respectively. In the same time decrease in lines $(1-5,2-5,2-4$, and $4-5)$ by $(2.13 \%$, $7.48 \%, 2.5 \%$, and $16.1 \%$ ), respectively, see figures ( $7 \& 8)$.

Table 4: variation in Power Flow for multi cases.

\begin{tabular}{|c|c|c|c|c|c|}
\hline Line & $\begin{array}{c}\text { MW } \\
\text { Limit }\end{array}$ & $\begin{array}{c}\text { Flow at } \\
\text { normal } \\
\text { state } \\
(\mathrm{MW})\end{array}$ & 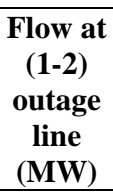 & $\begin{array}{c}\text { Flow at } \\
(1-4) \\
\text { outage } \\
\text { line } \\
(\mathrm{MW}) \\
\end{array}$ & $\begin{array}{c}\text { Flow at } \\
(3-6) \\
\text { outage } \\
\text { line } \\
(\mathrm{MW}) \\
\end{array}$ \\
\hline $1-2$ & 70 & 28.7 & 0.0 & 56.4 & 29.29 \\
\hline $1-4$ & 90 & 43.6 & 60.67 & 0.0 & 43.77 \\
\hline $1-5$ & 70 & 35.6 & 47.23 & 51.5 & 34.84 \\
\hline $2-3$ & 20 & 2.9 & -0.052 & 1.49 & $\begin{array}{c}-20.11 \\
\text { overload }\end{array}$ \\
\hline $2-4$ & 50 & 33.1 & 16.21 & $\begin{array}{c}66.44 \\
\text { overload }\end{array}$ & 32.27 \\
\hline $2-5$ & 40 & 15.5 & 10.12 & 12.93 & 14.34 \\
\hline $2-6$ & 60 & 26.2 & 22.72 & 24.54 & 51.79 \\
\hline $3-5$ & 30 & 19.1 & 15.73 & 17.49 & $\begin{array}{c}39.89 \\
\text { overload }\end{array}$ \\
\hline $3-6$ & 70 & 43.8 & 44.22 & 44.0 & 0.0 \\
\hline $4-5$ & 30 & 4.1 & 4.29 & -6.16 & 3.44 \\
\hline $5-6$ & 20 & 1.6 & 4.66 & 3.06 & 19.81 \\
\hline
\end{tabular}

Figure 2: Flow chart multi cases of line outage network. 


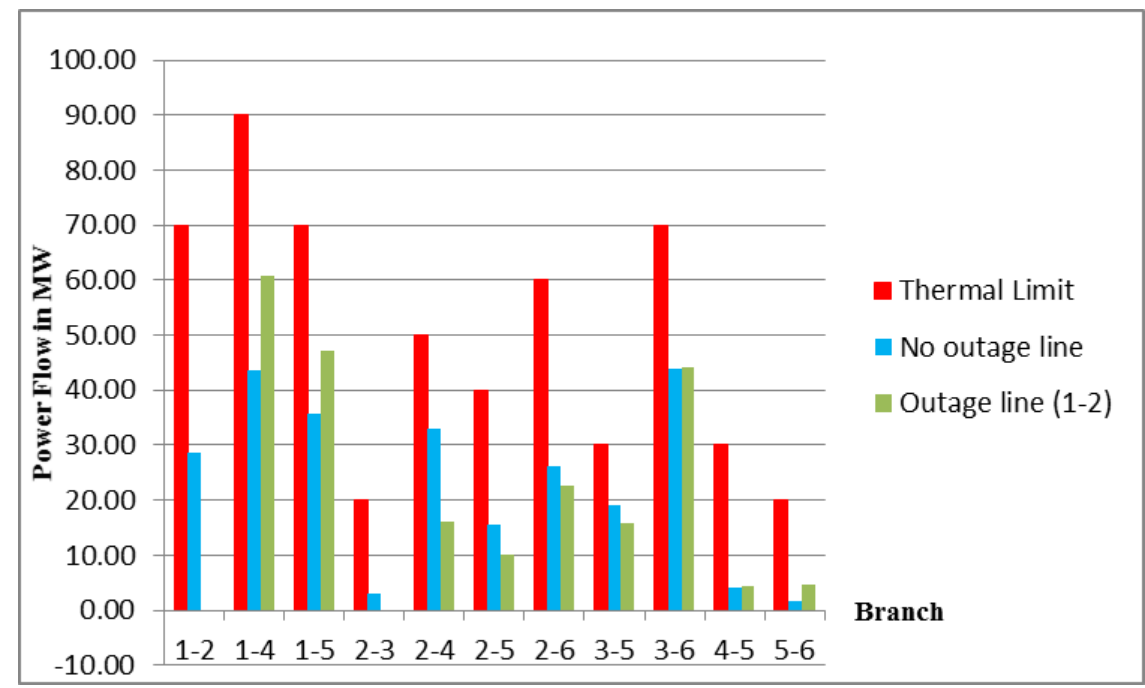

Figure 3: Power Flow for network lines system under outage line (1-2).

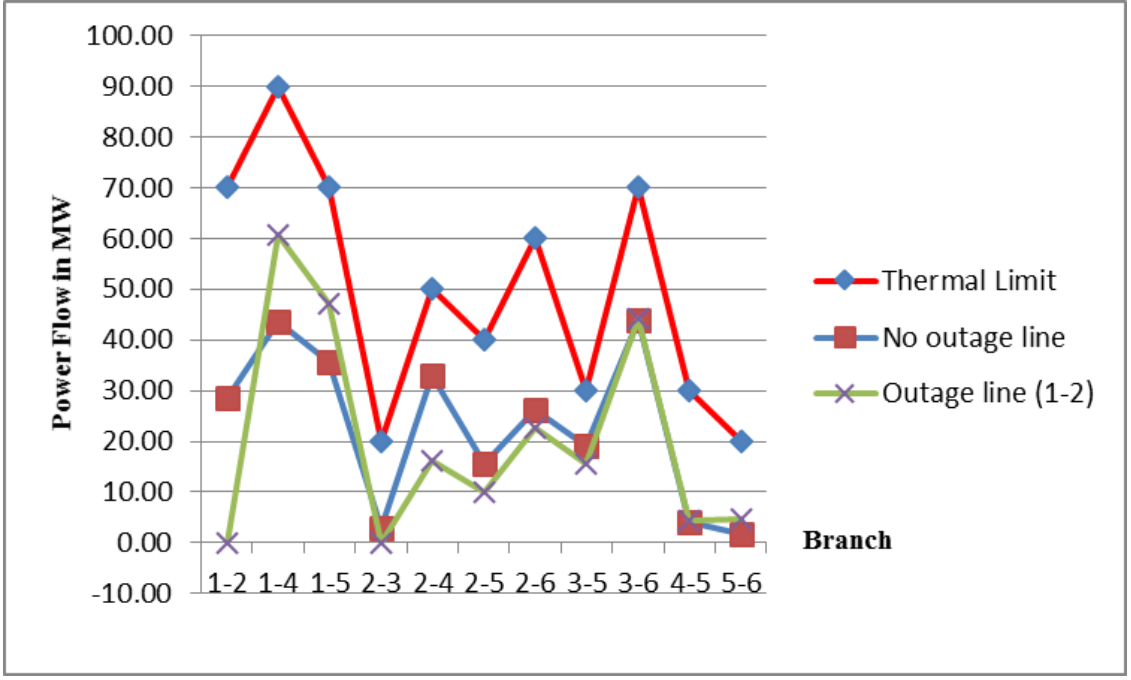

Figure 4: Value of power flow lines for network lines (case 1).

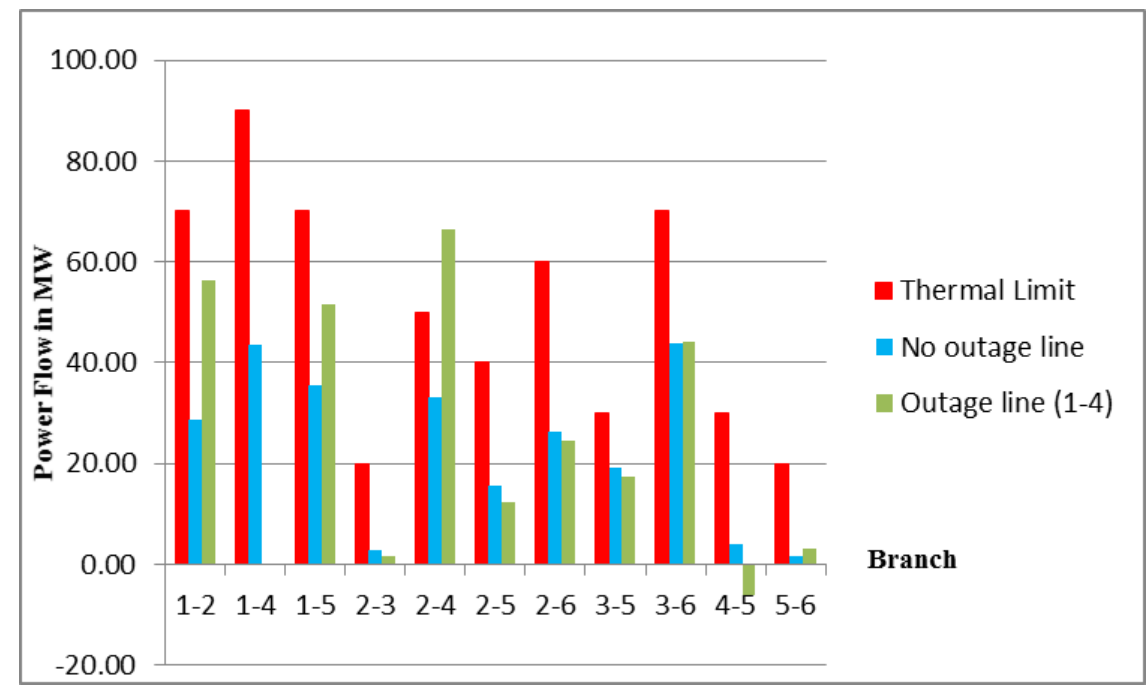

Figure 5: Power Flow for network lines system under outage line (1-4). 


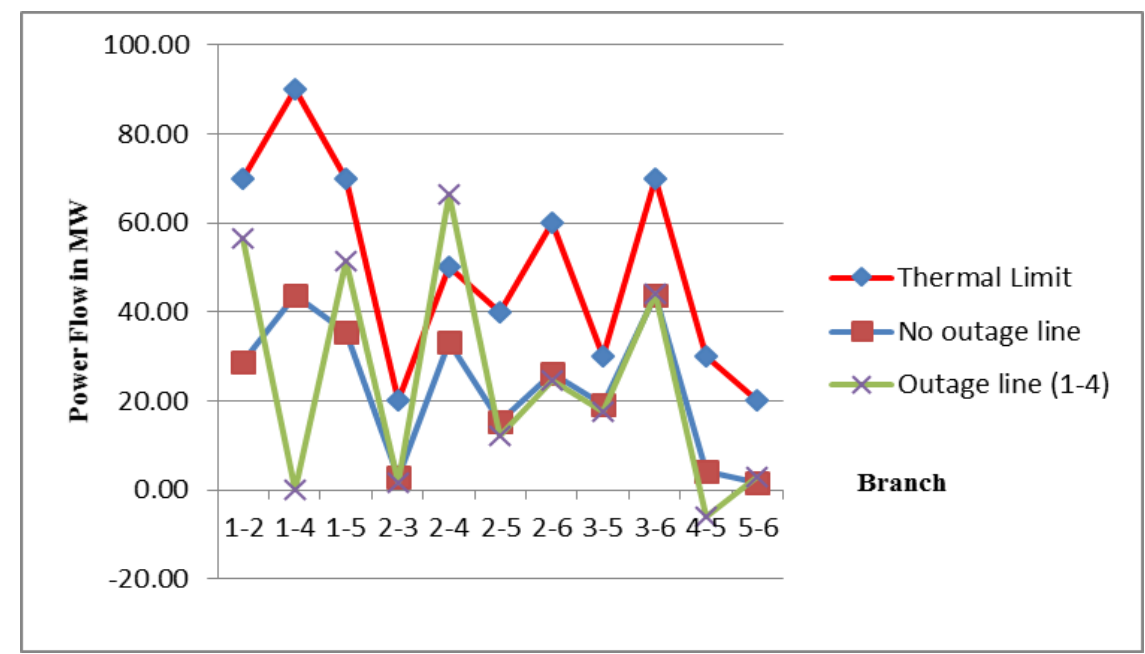

Figure 6: Value of power flow lines for network lines (case 2).

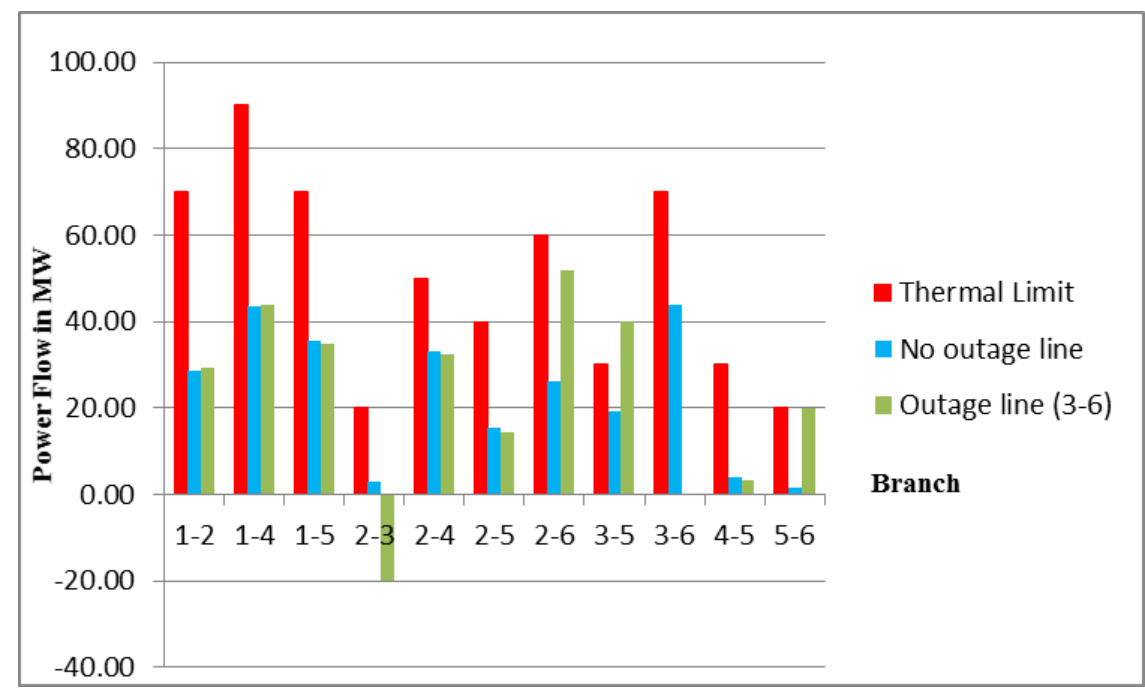

Figure 7: Power Flow for network lines system under outage line (3-6).

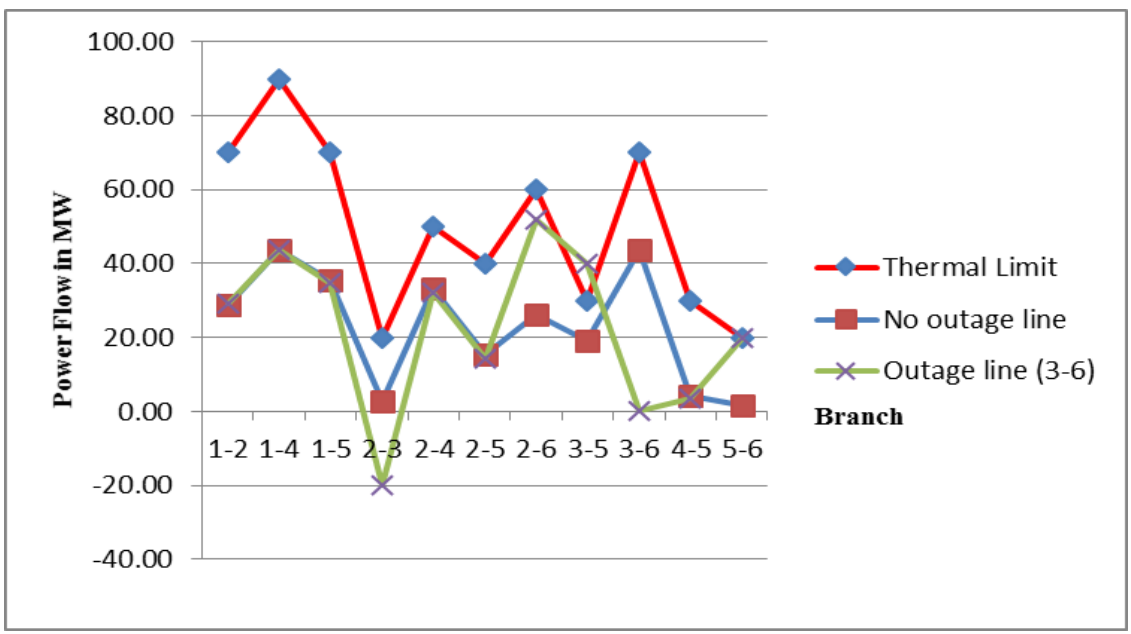

Figure 8: Value of power flow lines for network lines (case 3).

\section{CONCLUSION}

Through study and discussion out power flow lines for ensuring the network system, we suggest the following:

1. Control through regeneration organization in Buses.
2. Taking into consideration when designing the network system to the limits Permitted to lines of power flow to avoid a collapse in the network system.

3. Add lines to power flow in parallel-diagnosed lines, which happens rise in the power flow outside the 
limit to avoid weaknesses in the design of system network.

4. Add secondary line of power flow parallel to the main lines of power flow to avoid the outage occur frequently in some lines.

\section{REFERENCES}

[1] J.Z. Zhu, "Power System Optimal Operation," Tutorial of Chongqing University, 1990.

[2] Y. He , Z.Y. Wen , F.Y. Wang, and Q.H. Zhou, Power Systems Analysis, Huazhong Polytechnic University Press, 1985.

[3] A. Keyhani , A. Abur, and S. Hao , "Evaluation of Power Flow Techniques for Personal Computers ," IEEE Trans. on Power System, Vol. 4 , No. 2 , 1989 , pp. $817-826$.

[4] O. Alsac and B. Sttot, "Fast Decoupled power flow ," IEEE Trans. on Power System, Vol. 93 , 1974 , pp. 859 869.

[5] Wood, A.J. and B.F. Wollenberg, Power Generation, Operation, And Control: John Willey \& Sons. INC., Publication, p73, 1996.
[6] R.A.M. Van Amerongen , “ A General Purpose Version of the Fast Decoupled power flow, " IEEE Summer Meeting, 1988.

[7] A. Monticelli, A. Garcia, and O.R. Saavedra, “ Decoupled power flow,: Hypothesis,

Derivations, and Testing, " IEEE Trans. on Power System, Vol. 5 , No. 4 , 1990 , pp. $1425-1431$.

[8] A. Klos, A. Kerner, "The non-uniqueness of the load flow solution," in Proc. 1975 PSCC-5, vol. pp. 3.1-8, Cambridge, UK.

[9] C.L. DeMarco, T.J. Overbye, "Low voltage power flow solutions and their role in exit time based security measures for voltage collapse", in Proc. 27th Conf. Decision \& Control, Dec. 1988, Austin, TX.

[10] J.S. Thorp, S.A. Naqavi, "Load flow fractals", in Proc. 28th Conf. Decision and Control, Dec 1989, Tampa, FL.

[11] J.S. Thorp, S.A. Naqavi, "Load-flow fractals draw clues to erratic behavior", IEEE Computer Applications in Power, pp. 59-62, Jan. 1997. 